\title{
A crescente presença do Brasil no cenário científico internacional
}

A crescente produção científica do Brasil na área da saúde está intimamente ligada ao crescimento da pós-graduação no país. Há mais de 300 programas de mestrado e mais de 200 doutorados na área da saúde. O número de faculdades de medicina ultrapassa 100 , formando-se aproximadamente 10.000 médicos por ano. Contudo, somente oito faculdades de medicina, que podem ser identificadas como os grandes centros geradores de pesquisa científica na área médica, concentram 115 dos 128 pesquisadores qualificados como Nível I no Conselho Nacional de Pesquisa. Portanto, várias faculdades de medicina não estão vinculadas ao processo de produção de conhecimento, não permitindo uma integração da pesquisa e a formação na graduação. Considerandose o papel formativo que a pesquisa e o método científico têm sobre a educação do médico, conclui-se que uma parcela significativa dos médicos brasileiros é formada à margem desse sistema, não estando preparada para acompanhar e absorver as inovações no setor de saúde, altamente vinculadas ao desenvolvimento científico.*

O país busca, principalmente por meio da pós-graduação, consolidar sua base científica e formar recursos humanos capacitados para solucionar problemas de saúde regionais e nacionais. Um objetivo importante do sistema de formação é habilitar pesquisadores que possam cumprir tais objetivos. Esses produtores de conhecimento deverão ter domínio do estado de conhecimento na área que atuam, capacidade de originar questões coerentes e atualizadas com domínio metodológico para testá-las. Com a estruturação de linhas de pesquisa autóctones, tornam-se multiplicadores na formação de novos pesquisadores. A importância e o impacto do conhecimento originado devem ser referendados por avaliadores externos.

A produção científica na área médica cresceu proporcionalmente mais do que a produção do conjunto da ciência brasileira nos últimos 20 anos. O total de publicações na área médica, que perfazia $11 \%$ das 2.930 publicações ISI brasileiras no biênio 1981/1982, cresceu para $19 \%$ das 13.282 publicações
ISI no ano 2000 (aumento de 7,6 vezes). O índice global de crescimento nas diferentes áreas de conhecimento só foi ultrapassado pela engenharia (com crescimento de 8,5 vezes). Em relação à psiquiatria e saúde mental, houve crescimento de 3,2 vezes na comparação dos qüinqüênios 96-00/81-85, um crescimento importante, mas inferior se comparado às outras áreas da saúde. Um outro dado importante é que as publicações brasileiras em psiquiatria representam uma fração ainda reduzida do percentual global em medicina (1,9\% no Brasil versus $6 \%$ do percentual mundial). ${ }^{1}$ Com o aprimoramento da avaliação dos programas de pós-graduação no país, tendo-se como critério essencial a relevância da produção intelectual aferida pela qualidade dos veículos científicos, espera-se, em pouco tempo, uma redução dessa distância.

O incremento de produção na área médica tem sido também acompanhado de melhora na qualidade do produto. A área médica que perfazia $11 \%$ das citações brasileiras em 1982 foi responsável por $14 \%$ das citações brasileiras em 1998. O Brasil lidera a produção científica na América Latina, é responsável por $0,5 \%$ da produção global na área médica, ocupando a nona posição do planeta. O ritmo de produção científica no Brasil só é ultrapassado pela Coréia do Sul (relatório recente do ISI's National Science Indicators, no endereço eletrônico www.in-cites.com/countries/latin-america.html).

Os principais centros de produção científica na área médica são listados a seguir: Escola Paulista de Medicina da Universidade Federal de São Paulo, Faculdade de Medicina da Universidade de São Paulo e Instituto do Coração da Universidade de São Paulo, Faculdade de Medicina de Ribeirão Preto da Universidade de São Paulo, Fundação Oswaldo Cruz no Rio de Janeiro, Universidade Federal de Minas Gerais, Universidade Federal do Rio de Janeiro, Universidade Federal do Rio Grande do Sul, Faculdade de Ciências Médicas da Unicamp, Faculdade de Saúde Pública da USP, Universidade Federal da Bahia e Instituto Ludwig da Fundação Antonio Prudente.*

Pode-se notar, portanto, que a pesquisa na área médica é executada essencialmente nas universidades públicas e nos

*Zago MA, Carvalheiro JR, Luz PL, Mari JJ, Silva LJ. Ciência no Brasil: Medicina. Parcerias estratégicas (Centro de Estudos Estratégicos). Brasília, 2002 (no prelo). 
institutos de pesquisa e está vinculada aos programas de pósgraduação existentes no país. Embora sejam evidentes o aumento da produção científica e a posição de liderança na América Latina, países como México e Chile são mais eficientes em relação ao investimento que recebem para pesquisa. $\mathrm{O}$ investimento per capita em ciência e tecnologia é menor no Chile e no México do que no Brasil, acarretando menor custo per capita para um artigo de qualidade. ${ }^{2} \mathrm{~A}$ tendência na área de psiquiatria e saúde mental no Brasil é continuar avançando e ampliando sua presença nos cenários científico nacional e internacional. A Revista Brasileira de Psiquiatria, em sua busca de inserção e reconhecimento internacional, poderá, em breve, ser incluída no banco de dados do ISI, consequiência do bom nível da produção científica conquistada no país.

Jair de Jesus Mari Pesquisador I-A do CNPq Departamento de Psiquiatria da Unifesp/EPM

\section{Referências}

1. Chaimovich H, Leta J, Fonseca L, Rodrigues PS. Informação em Ciência, Tecnologia e Saúde. Academia Brasileira de Ciência; 2001. 